\title{
Why Do Chinese College Students Learn ESP: An Analysis of Language Learning Motivations within SDT Framework
}

\author{
Liangxing $\mathrm{Liu}^{1}$ \\ ${ }^{1}$ School of English and Education, Guangdong University of Foreign Studies, Guangzhou, Guangdong, P.R. \\ China \\ Correspondence: Liangxing Liu, School of English and Education, Guangdong University of Foreign Studies, \\ Guangzhou, Guangdong, P.R. China. E-mail: lxing.liu@gdufs.edu.cn
}

Received: January 23, 2016 Accepted: March 5, 2016 Online Published: March 8, 2016

doi: 10.5539/elt.v9n4p92 URL: http://dx.doi.org/10.5539/elt.v9n4p92

\begin{abstract}
This study mainly investigates the motivational characteristics of Chinese college students learning English for Specific Purposes (ESP). By critically examining and comparing Gardner's (1985) Integrative-Instrumental model and the Self-determination Theory (SDT) by Deci and Ryan(1985), the researcher finds out that the latter one is more comprehensive and applicable to the case of Chinese college ESP learners (the subjects). Thus the researcher develops a questionnaire within the SDT framework to analyze the subjects' motivations. Drawing upon a follow-up statistical analysis, the research discovers the motivational propensities of the subjects. A discussion of corresponding motivational methods to help improve the subjects' ESP learning is provided at the end of the article.
\end{abstract}

Keywords: language learning, motivations, ESP, Chinese college students, Self-determination Theory

\section{Introduction}

\subsection{Research Background}

As the pace of globalization quickens, countries around the globe try to educate their students with the current lingua franca of the world: the English language. As for China, the country's decision-makers expect its citizens to participate and compete more effectively and efficiently in international business arena. Therefore some Chinese universities are starting to promote courses that entail the learning of English for Specific Purposes (ESP), such as English for Marketing, English for Business Management and English for Finance etc. Though these courses are not beyond the framework of English language learning, they are still different from general English learning (EGP, English for General Purposes) in that they are aimed at training students with language knowledge and skills which will be useful in specific business areas. EGP, however, is suitable for anyone who wants to learn the English language for general communication in daily life. In short, EGP is for living, and ESP is for business.

In order to better educate the students with specific language competence and skills used in business, educators and researchers published different kinds of textbooks and research articles. However, it is rarely studied on how students in China, where English learning is regarded as the learning of foreign language (EFL) instead of a second language (L2), are motivated to learn such language courses in specific fields. Are the students intrinsically motivated to learn ESP or just extrinsically motivated by other factors? Are they just wishing to learn English as a tool for better jobs and greater salaries? Are they wishing to really integrate into the society of which the language is originated and mostly spoken (this type of motivation, named as Integrative motivation, is suggested by Gardner, 1972, as in the famous dichotomy of Integrative vs. Instrumental Motivations)?

There are already many motivational theories and models of motivation developed by educational and social psychologists, though they are not directly involved in L2 research (cf. Deci \& Ryan, 1985; Dörnyei, 1994a, 1994b; Gardner, 1972). However, it is still arguable whether motivational models used to gauge students in a specific socio-cultural and socio-educational context would be applicable to students in other contexts. For example, Gardner's Integrative-Instrumental model, which was developed on the basis of investigating the cases of Anglo-Canadians learning French, is often doubted for its applicability in other countries. In Canada, people live in a society with a bilingual context, where both English and French are official languages. Therefore, there 
exist different language communities and people often have to learn their second language (either English or French) to communicate with each other. According to Gardner, learners who display the characteristics of "integrativeness" tend to show an integrative orientation towards learning the language, favorable attitudes towards the target language community and a general openness towards other groups in general. In other words, "integrativeness" refers to the desire to assimilate into the target language community (Gardner \& Lambert 1972).

In China, Hua's (1998) study also revealed that the dominating motivation of the majority of English learners was a 'certificate motivation', a newly coined term referring to the motivation to obtain nationwide or globally recognized certificates of English proficiency. The background is that most college students in China are required to obtain a CET4 (College English Test Band 4) or CET6 or in some cases, BEC (Business English Certificate) to graduate and even to find a decent job. Similarly, Shi (2003) carried out a study of motivation among 78 students at a Chinese university and found that the majority of the participants agreed to the item 'I learn English in order to pass exams and obtain the diploma'. Shi therefore concludes that Chinese students had a 'certificate motivation', which is categorized as a sub-type of instrumental motivation by the researcher. In a study investigating the motivation types of English learning among Chinese undergraduates, Gao et al. (2004) suggest that ' $[\mathrm{t}]$ he classical instrumental-integrative division has not precisely accommodated the subtle and multi-folded motivations of the Chinese learners'.

This discrepancy of applicability might suggest that the differences in social milieu can be a source of the abovementioned conflicting findings. On the basis of the discussion, it is proved quite necessary to conduct empirical researches within a carefully chosen theoretical framework to help better understand motivations among college students in China's context. In view of the applicability of the theoretical framework, the researcher should choose one that provides stronger and more comprehensive explanatory power. Hence Gardner's Integrative-Instrumental model is not selected as the basis of the current study. Instead, the researcher decides to use the Self-Determination Theory (referred to as SDT hereinafter) (Deci \& Ryan, 1985, 1995).

The researcher hence adapts and develops a valid and reliable instrument within the SDT framework, rather than the instrumental-integrative division. It is based on the original research carried out by a Kimberly A. Noels (2003), to assess the different subtypes of intrinsic and extrinsic motivations of the Chinese college students learning ESP (referred to as the subjects hereinafter).

The SDT framework is believed to have several advantages over some other formulations of learner motivational orientations. According to Noels (2003), "SDT offers a parsimonious, internally consistent framework for systematically describing many different orientations in a comprehensive manner. It also offers considerable explanatory power for understanding why certain orientations are better predictors of relevant language learning variables (e.g., effort, persistence, attitudes) than others." The clear predictions of the framework may also be particularly valuable in applying the theory to language teaching and program development.

\subsection{Research Objectives}

This research is dedicated to discovering the underlying motivations of the subjects by analyzing data collected from a large number of samples together with materials collected from interviews with the subjects. The research questions can be summarized as follows:

1) Is the research instrument applicable to the students in China's context?

2) How might Self-Determination Theory inform understanding of motivations in ESP learning?

3) What are the specific motivational propensities of the subjects?

\section{Theoretical Framework}

Gardner and Lambert $(1959,1972)$ proposed a socio-educational model of analyzing learners' motivational orientations, namely the Integrative-Instrumental model. They suggested that an individual's motivation to learn an L2 is sustained by both attitudes toward the L2 community and the orientations. The first orientation, namely the integrative orientation refers to a desire to learn the L2 in order to identify with members from the L2 community. That means, the learners of a specific L2 highly appreciate the L2 society and their characteristics and are willing to be integrated into the target culture or society. The second orientation, namely the instrumental orientation refers to a desire to learn the L2 to achieve some practical goals, such as course credits in school, job advancement, or higher salaries etc. Gardner and Lambert (1972) suggested that individuals with an integrative orientation would demonstrate greater efforts in learning an L2, and thus, lead to better L2 learning outcome and competence. 
However, whether this hypothesis applies to most cases of L2 learning is still questionable. In other words, do most learners who embrace integrative orientation tend to perform better in L2 learning outcomes? This is a question that invoked many follow-up studies, the results of which have been inconsistent, with some proving the relative importance of the integrative orientation (e.g., Gardner \& Lambert, 1959), and others (e.g., Chihara \& Oller, 1978) disapproving. Either because the greater instrumental orientation led to L2 outcomes as well as, or even better than, the integrative orientation did; or because the integrative orientation even had a negative correlation with proficiency (which means greater integrative orientation led to worse L2 learning outcomes).

Some researchers (Clément \& Kruidenier, 1983) suggested that definitional problems and the ignorance of the influence of the social environment and settings were possibly the source of these incompatibilities. They studied the motivational orientations in French and English high school students of Spanish, English, and French, in either unilingual or multilingual contexts. They found that the integrative orientation appeared only in multicultural contexts among members of a clearly dominant group. Although it was originally suggested that the desire for contact and identification with members of the L2 group would be critical for L2 acquisition, it would now appear that it is not fundamental to the motivational process, but has relevance only in specific socio-cultural contexts. Considering the case in China, where the official language is only Mandarin, and English is only regarded as a foreign language (though important), the Chinese students might presumably hold less integrative orientations to English language learning.

In order to better account for the cases of motivational orientations, some researchers proposed alternative motivational models (e.g., Clément et al., 1994; Tremblay \& Gardner, 1995). One formulation that has received the attention of several scholars is the distinction between intrinsic and extrinsic motivations. Deci \& Ryan conceptualized such a model in their SDT $(1985,1995)$.

\subsection{A Self-Determination Approach to Motivation}

SDT represents a broad framework for the study of human motivations and personalities that concerns people's inherent and incessant growth tendencies and innate psychological needs. It is concerned with the motivation behind choices made without external influence or interference (Deci \& Ryan, 2002). SDT is a formal and comprehensive theory that defines intrinsic and various extrinsic sources of motivation, and a description of the respective roles of intrinsic motivation and different types of extrinsic motivation in cognitive and social development and in individual differences.

SDT focuses on the degree to which an individual's behavior is self-motivated and self-determined. According to SDT, there are two general types of motivation, namely intrinsic motivation and extrinsic motivation. The intrinsic motivation refers to performing an activity for its own sake because it is interesting and satisfying per se. The extrinsic motivation is based on external rewards to perform the task. Different types of motivations are described according to the degree they have been internalized or self-determined. According to the initiator of this theory, internalization refers to the active attempt to transform an extrinsic motive into personally endorsed values and thus assimilate behavioral regulations that were originally external (Ryan, 1995). Hence, these types of motivation are not categorically different, or totally opposed to each other, but rather lie along a continuum of self-determination.

More importantly, the SDT propositions also focus on how social and cultural factors facilitate or undermine people's sense of volition and initiative, in addition to their well-being and the quality of their performance. Conditions supporting the individual's experience of autonomy, competence, and relatedness, which are described as the three basic needs, are argued to foster the most volitional and high quality forms of motivation and engagement for activities, including enhanced performance, persistence, and creativity. In addition, SDT proposes that the degree to which any of these three psychological needs is unsupported or thwarted within a social context will have a strong negative impact on psychological wellness and motivation in that setting.

In short, SDT is a comprehensive theoretical framework which encompasses different parameters of motivation, such as the three basic human needs (competence, autonomy and relatedness) that should be satisfied to foster motivation and psychological well-being, the taxonomy of different motivations, and the consideration of the impact of different social and cultural contexts.

\subsubsection{Intrinsic Motivation}

According to SDT, intrinsic motivation (IM) refers to a natural, inherent drive to engage an activity because that activity is enjoyable, challenging and satisfying per se. As Deci and Ryan (1985) put it, IM is founded upon one's innate needs for competence and self-determination. The assumption is that whenever people are given the liberty to choose whatever activity to perform, they will prefer interesting ones. During this process, they will 
develop a sense of competence in themselves. Further, in order to complement it, Vallerand (Vallerand, Blais, Briere, \& Pelletier, 1989; Vallerand et al., 1992, 1993) proposed a threefold taxonomy of IM: the first type, IM-Knowledge, is the motivation for engaging an activity for the feelings associated with exploring new ideas and acquiring knowledge; the second type, IM-Accomplishment, refers to the sensations related to the attempts to fulfill and master a task or achieve a goal; the third type, IM-Stimulation, relates to motivation based simply on the sensations stimulated by performing the task, such as aesthetic appreciation or fun and excitement evoked by performance of the task per se. The common basis of these three subtypes is the enjoyable sensations experienced during the self-selected, self-initiated and interesting activity.

\subsubsection{Extrinsic Motivation}

In contrast to intrinsic motivation, extrinsic motivation refers to what drives one to act in order to achieve some 'instrumental end', such as earning a reward or avoiding a punishment. But this type of motivation does not necessarily imply a lack of self-determination in the behaviors performed. Instead, according to Deci and Ryan (1985), different subtypes of extrinsic motivation (EM) can be found along a continuum of self-determination to the degree to which they are internalized into the self-concept (that is, the extent to which the motivation is 'self-determined').

Within the domain of education, three levels of EM have been distinguished (Vallerand, 1997; Vallerand et al., 1989, 1992, 1993). The following subtypes of EM are ranked from the lowest to the highest level of self-determination: (1) external regulation, (2) introjected regulation, and (3) identified regulation.

The first subtype, external regulation, is the least autonomous and the least self-determined. It is performed purely because of external demand or possible reward. Such actions can be seen to have an externally perceived locus of causality (deCharms, 1968). It is defined as the reasons of actions that are determined by sources external to the person, not in the activity itself, such as tangible benefits or costs. In the case of learning a foreign language, it is assumed that if the external reason (e.g., scholarship or grants) for learning the language vanishes, there is no incentive to continue engagement in the learning process (cf. Gardner \& McIntyre, 1991).

A second subtype of extrinsic motivation which is more internalized into the self-concept is introjected regulation. Introjected regulation refers to reasons that pertain to performing an activity due to some type of 'pressure' that people have already incorporated into the self-concept, such that they compel themselves to carry out that activity. Although the 'source' of the pressure is internal, it is not self-determined because the people are reacting to a pressure, not acting on the basis of personal choice. A good example of this type of regulation is the students who practice a foreign language because they would feel ashamed if they could not speak that language. Learning would only take place as long as they feel the need to reduce guilt or shame brought about by the inability to perform.

The most self-determined form of extrinsic motivation is identified regulation. It is a more autonomously driven form of extrinsic motivation. It involves consciously valuing a goal or regulation so that said action is accepted as personally important, or of values in the perceived self-concept. At this point, individuals invest energy in an activity because they have chosen to do so for personally relevant reasons. In this situation, students would carry out the activity because of its importance for achieving a valued goal. For instance, language learners who feel that fluency and decent accent are important aspects of their educational development will endure repetitive oral exercises in the interest of attaining this level of competence.

At last, Deci and Ryan (1985) contrasted all types of IM and EM with amotivation. Amotivation refers to the situation in which people see no relation between their actions and the consequences of those actions; the consequences are seen as arising as a result of factors beyond their control. In other words, for example, some foreign language learners may not be aware of the reasons why they perform such learning, they also cannot feel the ability to control the consequences of such actions. In such a situation, people have no reason, intrinsic or extrinsic, for performing the activity, and they would be expected to quit the activity as soon as possible. However, unlike in other fields of SDT application, amotivation is not frequently found in foreign language learners.

\subsubsection{IM, EM, and Language Learning}

Some researchers have suggested that IM and EM may be useful constructs for understanding L2 motivation (e.g., Brown, 1994; Crooks \& Schmidt, 1991; Dickinson, 1995; Dornyei, 1994a; Kamada, 1986). Indeed, some empirical evidence suggests that the distinction between intrinsic and extrinsic goals can be of use in L2 learning outcome prediction. In one empirical research, Ramage (1990) found that continuing students were more motivated to learn language for language's sake--that is, they were more intrinsically motivated than 
discontinuing students. Discontinuing students had a stronger interest in language learning as a means to achieve other goals (e.g., academic credit, scholarship); that is, they tended to be more extrinsically motivated. According to Ehrman's (1996) report, among other factors, intrinsic motivation correlated positively with end-of-training speaking and reading proficiencies. Thus, SDT framework, especially the intrinsic/extrinsic distinction, seems able to be utilized in predicting L2 learning outcomes.

\section{Methodology}

\subsection{Subjects}

Non-English major students registered in ESP classes in a globalization-oriented university were asked to participate in the study. This university is located in South China and most of the students speak Chinese as the mother tongue. But all students are required to master an L2, particularly English, in order to improve and enhance their competiveness in the global employment market, as stipulated by the university.

For the present purposes, only students who are Chinese speakers (that is, both their mother tongue and language used most often were Chinese) and who are learning ESP were included for the analyses. So the subjects of this study are those who major in Marketing, Finance, and Business Management etc., resulting in a sample size of 558 participants. The subjects are junior students aged from 18 to 20 . The mean length of time spent learning English as a foreign language is more than 10 years. They ranged in age from 19-21, with a mean age of 20 years. Most of them are expected to pass nationwide college English exams in China (College English Test, abbreviated as CET4 \& CET6). Some are expecting to pass BEC (Business English Certificate by Cambridge).

\subsection{Materials}

The material used in this study consists of a questionnaire which is formulated on the basis of a questionnaire presented in Noels' research paper (Noels, 2003), the title of which is Language Learning Orientations Scale-Intrinsic Motivation, Extrinsic Motivation, and Amotivation Subscales (LLOS-IEA). The researcher of this present study adopted the idea and redesigned the questionnaire to suit the socio-educational situation of Chinese students, especially considering the students' understanding of the specific items in the questionnaire. The language used is Chinese, which is meant to better aid the understanding of the subjects. Before formally issuing the questionnaire, the researcher conducted pilot studies to select the most suitable items to be included in the questionnaire, and omit those that were believed to be not representing the mainstream situation or confusing items. Some items were adjusted several times to better reflect the socio-educational context that the students are in. A description of the scales and items used, along with the Cronbach alpha, follows.

The questionnaire contained subscales intended to assess Amotivation, the three subtypes of EM, including External, Introjected, and Identified regulation, and the three subtypes of IM, including Knowledge, Accomplishment, and Stimulation (see the Appendix for sample items). The items were randomly ordered throughout the whole questionnaire. The students were asked to rate the extent to which the proposed reason applied to them by using the same type of 5-point Likert scale as described. A high score suggested a high degree of correspondence between the proposed reason and the students' reason for studying an ESP.

\subsection{Procedure}

The questionnaire was uploaded to an online surveying website, and then the researcher sent the link of the questionnaire to target students via SNS apps, and asked them to finish it whenever they were free, off regular class time. The purpose of choosing off-class time to conduct the study is to reduce subjects' anxiety at the researcher's presence. The researcher also told them that their participation was voluntary and that their responses would remain confidential and be used only for academic purposes. The data were collected automatically from the online survey system. And the following analysis was conducted on the data reformatted from the raw data. Then the researcher used SPSS to analyze the validity, credibility, correlation and interrelation of different items.

At the same time, the researcher also organized several focus groups to interview the respondents to the questionnaire. The researcher randomly chose some interviewees out of the large number of respondents to form into several focus groups. Various questions concerning the topics of ESP learning and their motivations are asked, their responses are also taken down for further analysis.

\section{Results and Discussion}

The primary purpose of this project is to assess the reliability, validity and applicability of the instrument for discovering Chinese college ESP learners' structure of motivation, especially in terms of the subtypes of intrinsic and extrinsic motivations empirically. Therefore, in order to find out a clear and reliable subscale for each 
motivation subtype, the researcher conducted exploratory factor analyses and reliability analyses. To assess the construct validity of the subscales, they were correlated with one another, and this process was repeated many times (i.e., iterative process) to determine the best items for each subscale. The details of the research results will be presented in the following sections.

\subsection{Validity and Reliability Analyses}

A prerequisite of any exploratory factor analysis--the KMO and Bartlett's Test was conducted prior to any other steps. The results show that the KMO measure of sampling adequacy was 0.952 , which is believed to be an excellent sign showing that these variables are very suitable for an exploratory factor analysis. At the same time, the Bartlett's Test of Sphericity scores 8443.079, which further illustrates its suitability for such an analysis (See Table 1).

Table 1. KMO and Bartlett's Test

Kaiser-Meyer-Olkin Measure of Sampling Adequacy. .952

\begin{tabular}{lll}
\hline & Approx. Chi-Square & 8443.079 \\
Bartlett's Test of Sphericity & df & 253 \\
& Sig. & .000 \\
\hline
\end{tabular}

Upon completion of this important aspect, exploratory factor analyses were conducted using Maximum Likelihood Extraction technique followed by Varimax rotation. The aim is to determine the best items for each of the motivation subscales. These analyses were carried out for intrinsic and extrinsic subscales respectively. An iterative process was involved in the analysis strategy. Any item that did not contribute sufficiently to the solution was eliminated, and then the correlation matrix was reanalyzed. The whole process was repeated until there were at least three items to define each subscale.

One factor analysis was conducted with all the intrinsic and extrinsic items after they were decided. Processed with the Maximum Likelihood extraction technique, the results of this analysis yielded seven factors accounting for $64.76 \%$ of the variance (See Table 2). An examination of the factor structure revealed that the factors represented the seven hypothesized motivational constructs as illustrated earlier in this paper. These results basically support the distinctiveness of each of the subscales (See Table 3). The seven factors do respond distinctively to clusters of items that stand for the hypothesized motivational constructs. In this analysis, only the loadings greater than 0.30 are retained, those lower than 0.30 are omitted. As illustrated in the Table 3 , those factors.

A reliability analysis was conducted to determine whether The Cronbach alpha index of internal consistency, shown in Table 3, was acceptable for all subscales, varying between 0.760 and 0.857 , and the total Cronbach alpha for all the subscales was calculated as 0.951 , a very high number in terms of reliability. These show that the internal consistency of the data is very reliable, and that all the seven factors have relatively high reliability, the results are relatively convincing.

In Table 5, the means, standard deviation, skewness and kurtosis are shown for the 23 items. If the means higher than 3.8 are regarded as high score, than it can be stated that the means of the three items within the Amotivation subscale are high. This meets the researcher's expectation that the participants were mostly aware of the situation when they attended the university where English language learning is a compulsory condition for future study, and where certain credits ( 24 credits for non-English majors) gained from English courses are required to obtain a decent diploma. These students, either intrinsically or extrinsically motivated, can be presumed to be little motiveless (or amotivated as stated in the research) with regard to the learning of ESP. Three of the four items within the External Regulation subscale, have means greater than 3.8. Considering that External Regulation is the least self-determined form of motivation, thus these numbers indicate that the participants are greatly motivated by external demand or possible reward. For example, they may want to learn ESP with the hope to find a good job with high salary. But the Introjected Regulation subscale only shows one item with a mean higher than 3.8. The item is IRQ9, which describes the students' intention to learn ESP well to ensure their identity of being part of the global business community. This is the kind of behavior where people feel motivated to demonstrate ability to maintain self-worth. But in the rest two items within this subtype, the participants demonstrated a low motivation in terms of avoiding losing face in international business activities. The point is 
maybe they are not yet involved in such kind of activities, and that to certain degree, they lack such contextual environment to engage in communicative activities with foreign individuals who speak English.

In terms of the Identified Regulation subscale, two out of the three items have scores higher than 4, which indicate that the participants are highly motivated to learn ESP because they realize the importance of learning ESP, and try to internalize the need as part of the self-concept. But item IDRQ13, which states that learning ESP is a symbol of educational level and social status, has a very low mean. This might be interpreted as the participants generally do not regard learning ESP as a means to improve one's social status, or do not take it as one important aspect of one's self-concept.

When it comes to the subscales of Intrinsic Motivation, all Intrinsic Motivation-Knowledge and Intrinsic Motivation-Accomplishments items have scores higher than 3.8. It suggests that probably the participants are motivated to learn the knowledge per se. In other words, the pursuit of ESP knowledge is internalized. They have high expectation of learning some knowledge from ESP courses. As for Intrinsic Motivation-Accomplishments, the high scores of means may suggest that participants are in want of challenges in learning ESP. Since this subtype of motivation is more self-determined, the participants are driven by an inner demand to learn ESP. They are also aware that ESP is not a simple course; hence they regard it as a challenge, which should be met in order to achieve a sense of achievement.

The last subtype of intrinsic motivation is named Intrinsic Motivation-Stimulation. Two out of the four items within this group have means higher than 4 . It is the most self-determined form of intrinsic motivation. Individuals take behaviors as one part of the self-concept. Under this condition, an individual perform an activity for the enjoyment in the activity itself. Considering the scores of the items, one can conclude that the participants are fairly motivated by this subtype, but not very strong. Possibly because they normally regard English language learning as a task, a challenge, but not a beautiful or interesting thing that can boost their pleasure.

Table 2. Total variance explained

\begin{tabular}{lllllll}
\hline & \multicolumn{3}{l}{ Initial Eigenvalues } & \multicolumn{3}{l}{ Rotation Sums of Squared Loadings } \\
\cline { 2 - 6 } Factor & Total & \% of Variance & Cumulative \% & Total & \% of Variance & Cumulative \% \\
\hline 1 & 11.422 & 49.660 & 49.660 & 3.356 & 14.592 & 14.592 \\
2 & 1.454 & 6.321 & 55.982 & 2.477 & 10.770 & 25.363 \\
3 & 1.210 & 5.260 & 61.241 & 2.206 & 9.590 & 34.953 \\
4 & .918 & 3.991 & 65.233 & 2.147 & 9.336 & 44.289 \\
5 & .859 & 3.733 & 68.965 & 1.991 & 8.656 & 52.945 \\
6 & .801 & 3.484 & 72.450 & 1.384 & 6.019 & 58.963 \\
7 & .600 & 2.610 & 75.060 & 1.334 & 5.798 & 64.762 \\
8 & .580 & 2.521 & 77.581 & & & \\
9 & .541 & 2.352 & 79.932 & & & \\
10 & .513 & 2.229 & 82.162 & & & \\
11 & .483 & 2.098 & 84.260 & & & \\
12 & .439 & 1.909 & 86.169 & & & \\
13 & .429 & 1.867 & 88.036 & & & \\
14 & .386 & 1.679 & 89.715 & & & \\
15 & .345 & 1.498 & 91.213 & & & \\
16 & .331 & 1.441 & 92.654 & & & \\
17 & .300 & 1.304 & 93.959 & & & \\
\hline
\end{tabular}




\begin{tabular}{llll}
\hline 18 & .283 & 1.231 & 95.189 \\
19 & .269 & 1.168 & 96.358 \\
20 & .244 & 1.060 & 97.418 \\
21 & .227 & .989 & 98.407 \\
22 & .202 & .880 & 99.287 \\
23 & .164 & .713 & 100.000 \\
\hline
\end{tabular}

Note. Extraction Method: Maximum Likelihood.

Table 3. Pattern Matrix, communalities $(\eta 2)$, and factor variance for the final maximum likelihood factor analysis of amotivation, intrinsic motivation, and extrinsic motivation items

\begin{tabular}{|c|c|c|c|c|c|c|c|c|}
\hline & & & & Factors & & & & \\
\hline Items & 1 & 2 & 3 & 4 & 5 & 6 & 7 & $\eta^{2}$ \\
\hline IMSQ22 & 0.654 & & & & & & & 0.547 \\
\hline IMSQ21 & 0.615 & & & & & & & 0.695 \\
\hline IMSQ23 & 0.392 & & & & & & & 0.592 \\
\hline AQ2 & & 0.903 & & & & & & 0.587 \\
\hline AQ1 & & 0.609 & & & & & & 0.563 \\
\hline AQ3 & & 0.466 & & & & & & 0.382 \\
\hline ERQ5 & & & 0.695 & & & & & 0.51 \\
\hline ERQ6 & & & 0.63 & & & & & 0.559 \\
\hline ERQ4 & & & 0.518 & & & & & 0.487 \\
\hline ERQ7 & & & 0.411 & & & & & 0.439 \\
\hline IRQ10 & & & & 0.652 & & & & 0.577 \\
\hline IRQ8 & & & & 0.62 & & & & 0.476 \\
\hline IRQ9 & & & & 0.519 & & & & 0.622 \\
\hline IMKQ14 & & & & & 0.746 & & & 0.623 \\
\hline IMKQ15 & & & & & 0.652 & & & 0.637 \\
\hline IMKQ16 & & & & & 0.421 & & & 0.6 \\
\hline IDRQ12 & & & & & & 0.663 & & 0.668 \\
\hline IDRQ13 & & & & & & 0.475 & & 0.515 \\
\hline IDRQ11 & & & & & & 0.447 & & 0.666 \\
\hline IMAQ17 & & & & & & & 0.641 & 0.756 \\
\hline IMAQ18 & & & & & & & 0.593 & 0.715 \\
\hline IMAQ19 & & & & & & & 0.575 & 0.597 \\
\hline
\end{tabular}

Note. Suggested factor names: 1-Intrinsic Motivation-Stimulation; 2-Amotivation;

3-External Regulation; 4-Introjected Regulation; 5-Intrinsic Motivation-Knowledge;

6-Identified Regulation; 7-Intrinsic Motivation-Accomplishment. 
Table 4. Reliability statistics

\begin{tabular}{ll}
\hline Subscales & Cronbach's Alpha \\
\hline 1 Amotivation & 0.784 \\
2 External Regulation & 0.811 \\
3 Introjected Regulation & 0.814 \\
4 Identified Regulation & 0.76 \\
5 Intrinsic Motivation-Knowledge & 0.838 \\
6 Intrinsic Motivation-Accomplishment & 0.857 \\
7 Intrinsic Motivation-Stimulation & 0.823 \\
Total & 0.951 \\
\hline
\end{tabular}

Table 5. Statistics

\begin{tabular}{|c|c|c|c|c|}
\hline & Mean & SD & Skewness & Kurtosis \\
\hline AQ1 & 4.12 & 0.905 & -1.177 & 1.698 \\
\hline AQ2 & 3.98 & 0.921 & -0.984 & 1.05 \\
\hline AQ3 & 3.89 & 1.103 & -0.997 & 0.29 \\
\hline ERQ4 & 3.54 & 1.033 & -0.297 & -0.568 \\
\hline ERQ5 & 3.96 & 0.821 & -0.696 & 0.8 \\
\hline ERQ6 & 3.95 & 0.853 & -0.864 & 1.156 \\
\hline ERQ7 & 4.06 & 0.863 & -1.039 & 1.311 \\
\hline IRQ8 & 3.59 & 0.997 & -0.441 & -0.393 \\
\hline IRQ9 & 4.02 & 0.821 & -0.957 & 1.499 \\
\hline IRQ10 & 3.68 & 0.962 & -0.517 & -0.124 \\
\hline IDRQ11 & 4.13 & 0.847 & -1.08 & 1.516 \\
\hline IDRQ12 & 4.22 & 0.742 & -1.231 & 3.075 \\
\hline IDRQ13 & 3.42 & 1.074 & -0.341 & -0.648 \\
\hline IMKQ14 & 3.93 & 0.884 & -0.924 & 1.084 \\
\hline IMKQ15 & 4.02 & 0.804 & -1.011 & 1.716 \\
\hline IMKQ16 & 4 & 0.861 & -1.104 & 1.723 \\
\hline IMAQ17 & 4.05 & 0.854 & -1.092 & 1.614 \\
\hline IMAQ18 & 3.9 & 0.9 & -0.833 & 0.709 \\
\hline IMAQ19 & 3.88 & 0.856 & -0.81 & 0.911 \\
\hline IMSQ20 & 3.45 & 0.996 & -0.244 & -0.571 \\
\hline IMSQ21 & 4.09 & 0.786 & -1.178 & 2.63 \\
\hline IMSQ22 & 3.7 & 0.999 & -0.681 & 0.054 \\
\hline IMSQ23 & 4.18 & 0.755 & -1.146 & 2.505 \\
\hline
\end{tabular}

Note. AQ: Amotivation Question;

ERQ: External Regulation Question;

IRQ: Introjected Regulation Question;

IDRQ: Identified Regulation Question;

IMK: Intrinsic Motivation-Knowledge;

IMAQ: Intrinsic Motivation-Accomplishment;

IMSQ: Intrinsic Motivation-Stimulation. 


\section{Conclusion}

The results of the analyses suggest that learner motivation can be validly assessed using the intrinsic and extrinsic subtypes. The factor analyses demonstrated a clear distinction between the subscales. According to the results, the students are aware that they need to learn ESP. But the students interviewed in focus group after fulfilling the questionnaire mentioned that though they knew the necessity to learn ESP, they found it difficult to learn, and they wanted to know more about how to self-study the ESP course after class. Besides, the students seemed to be equally motivated extrinsically and intrinsically. They learned the ESP course with the expectation of earning external rewards or avoiding punishments or losing face. This result meets the researcher's original expectation. They also internalized some extrinsic behaviors into the self-concept to certain extent.

To a certain degree, it is safe to say that students were also intrinsically motivated to learn the course. But that they took the course learning itself as a challenge that should be met to help them gain the sense of achievement or accomplishment. They were driven by the quest for knowledge, and this quest for knowledge is not confined to ESP learning itself. As put by one student interviewed, he tended to learn ESP since he thought it was challenging and the knowledge learned would be useful in his future work and study. Therefore it is not unjustified to conclude that students were motivated in a mixed manner. They were not very clear about their motivational subtypes and tended to mix different subtypes up in their description.

According to Hua's (1998) study, the dominating motivation of the majority of English learners is named 'certificate motivation', which is more extrinsic type of motivation. But in the interviews, most students responded that they had already passed the CET4 or CET6, so the evidence found in the students is not sufficient to justify such a type of motivation, at least in this group of students. Instead, they tended to care more about whether this learning could equip them with real knowledge and real skills or not. The reason is that they focus on the future work and study instead of the tests. Hence it is fair to draw the conclusion that most students were motivated and aware of the importance of the learning of ESP courses. It may suggest that, to foster sustained learning, it may be insufficient to just convince students that ESP learning is personally important for them; they may need to be persuaded that it is also interesting and enjoyable.

The next aspect that needs the attention of educators is that, in the case of Chinese students, they tend to be not so aware of the self-worth and not caring too much about losing face due to lack of proficiency in ESP in international business activities, it is necessary to create opportunities to get them involved in such activities. Though it is really not easy to do so, at least the educators can try to simulate occasions in class for them to practice. Under peer pressure and the stress of speaking in public, the students may also have the chance to realize the importance of mastering ESP. In other words, the educators should provide supportive contextual environment to help students practice and stimulate them to master the ESP better.

According to the SDT, the more internalized the reason for language learning, the more comfortable and persevering students claimed to be. Such a pattern might suggest that students who learn a foreign language in an autonomy-supportive environment (contextualized and socialized environment in the case of Chinese students) where feedback enhances their sense of competence in the learning task are likely to be those students who learn because it is pleasurable or because it appeals to their self-concept. This can also enhance their sense of relatedness, and help improve their self-efficacy. They are also less likely to feel the anxiety in the learning process, and less likely to give up. It seems that language educators should design language programs that emphasize autonomy to help foster student motivation and possible progress.

Second, it is necessary to consider the generalizability of the present findings, and indeed, of the SDT framework, to other language students in different socio-cultural or socio-educational contexts. The present findings describe the motivational properties of Chinese students in an EFL context. It can be regarded as a complement to researchers carried in other contexts. For example, a research conducted by Noels (2003) on the Anglo-Canadian students in a bilingual context; Clément and Kruidenier (1983) have indicated that some orientations may be found more reliably in some contexts than in others.

In conclusion, this article has presented a theoretical framework that can distinguish the motivational properties and propensities of language students. Under the current socio-educational constraints, the Chinese college learners exhibit a well-understood pattern of motivations.

The shortcoming and regret of the present study is that the researcher failed to conduct a research to investigate the relationship between learning outcomes and the students' motivational propensities. This failure is due to the lack of a justifiable and convincing instrument to assess the learning of so many students. An additional reason is that it is not justified whether the test should be conducted once only or twice, one before the learning of ESP, and the other after a period of learning. 
At last, it is suggested that in order to improve the learning motivation of ESP students, specific teaching strategies are recommended, such as creating a supportive and non-threatening learning environment, maximizing learners' participation and language competence, enhancing the cohesiveness and positive interdependence of learning groups, as well as facilitating learners' autonomy.

\section{Acknowledgements}

This research is funded by the Guangdong Provincial Research Project of Teaching Reform, Ref. \#GDJG20142207; supported by Youth Union Grant, Ref. \#13s5, Guangdong University of Foreign Studies, China.

\section{References}

Brown, H. D. (1994). Teaching by principles. Englewood Cliffs, NJ: Prentice Hall.

Clément, R., \& Kruidenier, B. G. (1983). Orientations in second language acquisition: I. The effects of ethnicity, milieu and target language on their emergence. Language Learning, 33, 272-291. http://dx.doi.org/10.1111/j.1467-1770.1983.tb00542.x

Crooks, G., \& Schmidt, R. W. (1991). Motivation: Reopening the research agenda. Language Learning, 41, 469-512. http://dx.doi.org/10.1111/j.1467-1770.1991.tb00690.x

deCharms, R. (1968). Personal causation. New York: Academic Press.

Deci, E. L., \& Ryan, R. M. (1985). Intrinsic motivation and self-determination in human behavior. New York: Plenum.

Deci, E. L., \& Ryan, R. M. (1995). Human autonomy: The basis for true self-esteem. In M. H. Kernis (Ed.), Efficacy, agency and self-esteem (pp. 31-49). New York: Plenum. http://dx.doi.org/10.1007/978-1-4899-2271-7

Deci, E. L., \& Ryan, R. M. (2002). Handbook of Self-determination research. Rochester, NY: University of Rochester Press. http://dx.doi.org/10.1007/978-1-4899-1280-0_3

Dickinson, L. (1995). Autonomy and motivation: A literature review. System, 23, 165-174. http://dx.doi.org/10.1016/0346-251X(95)00005-5

Dörnyei, Z. (1994a). Motivation and Motivating in the foreign language classroom. Modern Language Journal, 78, 273-284. http://dx.doi.org/10.1111/j.1540-4781.1994.tb02042.x

Dörnyei, Z. (1994b). Understanding L2 motivation: On with the challenge. Modern Language Journal, 78, 515-523. http://dx.doi.org/10.1111/j.1540-4781.1994.tb02071.x

Ehrman, M. (1996). An exploration of adult language learner motivation, self-efficacy, and anxiety. In J. L. Oxford (Ed.), Language learning motivation: Pathways to the new century (pp. 81-103). Honolulu: University of Hawaii Press.

Chihara, I., \& Oller, J. W. (1978). Attitudes and attained proficiency in EFL: A sociolinguistic study of adult Japanese speakers. Language Learning, 28, 55-68. http://dx.doi.org/10.1111/j.1467-1770.1978.tb00304.x

Gao, Y., Zhao, Y., Cheng, Y., \& Zhou, Y. (2004). Motivational types of Chinese University Undergraduates. Asian Journal of English Language Teaching, 14, 45-64.

Gardner, R. C., \& Lambert, R. C. (1959). Motivational variables in second language acquisition. Canadian Journal of Psychology, 13, 266-272. http://dx.doi.org/10.1037/h0083787

Gardner, R., \& Lambert, E. (1972). Attitudes and Motivation in Second Language Learning. Rowley: Newbury.

Gardner, R. C. (1985). Social Psychology and Second Language Learning: The Role and Attitudes and Motivation. London: Edward Arnold.

Gardner, R. C., \& MacIntyre, P. D. (1991). An instrumental motivation in language study: Who says it isn't effective? Studies in Second Language Acquisition, 13, 57-72. http://dx.doi.org/10.1017/S0272263100009724

Hua, H. (1998). A review of research on English learning motivation and strategies. Waiyujie, 3, 44-47.

Kamada, L. D. (1986, November). Intrinsic and extrinsic motivational learning process: Why Japanese can't speak English. Paper presented at the Japan Association of Language Teachers' International Conference on Language Teaching and Learning, Seirei Gakuen, Hamamatsu, Japan.

Noels, K., Pelletier, A., Clément, L. G., \& Vallerand, R. J. (2003). Why are you learning a second language? 
Motivational orientations and self-determination theory. Language Learning, 53, 33-63. http://dx.doi.org/10.1111/1467-9922.53223

Ramage, K. (1990). Motivational factors and persistence in foreign language study. Language Learning, 40, 189-219. http://dx.doi.org/10.1111/j.1467-1770.1990.tb01333.x

Ryan, R. (1995). Psychological needs and the facilitation of integrative processes. Journal of Personality, 63, 397-427. http://dx.doi.org/10.1111/j.1467-6494.1995.tb00501.x

Tremblay, F., \& Gardner, C. (1995). Expanding the motivation construct in language learning. The Modern Language Journal, 79, 505-518. http://dx.doi.org/10.1111/j.1540-4781.1995.tb05451.x

Shi, Y. (2003). A survey of University Students’ English Learning Motivation. Guowai Waiyu Jiaoxue (Language Teaching in Foreign Coutries), 4, 8-11.

Vallerand, R. J., Blais, M. R., Brière, N. M., \& Pelletier, L. G. (1989). Construction et validation de l'Echelle de motivation en education (EME) [Construction and validation of the Academic Motivation Scale]. Canadian Journal of Behavioural Science, 21, 323-349. http://dx.doi.org/10.1037/h0079855

Vallerand, R. J., Pelletier, L. G., Blais, M. R, Brière, N. M., Senécal, C., \& Vallières, E. F. (1992). The Academic Motivation Scale: A measure of intrinsic, extrinsic, and amotivation in education. Educational and Psychological Measurement, 52, 1003-1007. http://dx.doi.org/10.1177/0013164492052004025

Vallerand, R. J., Pelletier, L. G., Blais, M. R., Brière, N. M., Senécal, C., \& Vallières, E. F. (1993). On the assessment of intrinsic, extrinsic and amotivation in education: Evidence on the concurrent and construct validity of the Academic Motivation Scale. Educational and Psychological Measurement, 53, 159-172. http://dx.doi.org/10.1177/0013164493053001018

Vallerand, R. J. (1997). Toward a hierarchical model of intrinsic and extrinsic motivation. In M. P. Zanna (Ed.), Advances in experimental social psychology (Vol. 29, pp. 271-360). San Diego, CA: Academic Press. http://dx.doi.org/10.1016/s0065-2601(08)60019-2

\section{Appendix A:}

\section{Original Questionnaire in Chinese}

\section{关于专门用途英语学习动机的问卷调查}

同学您好!

我们是广东外语外贸大学的一个学术研究团队, 正在进行一项关于中国非英语专业大学生习专门用途英 语 (English for Specific Purposes, 简称 ESP, 如营销英语、管理英语等) 的学习动机调查, 诚挚邀请您利 用几分钟的时间帮忙填写这份简单的问卷。

请根据您的实际想法选择每句描述后的一个选项; 答案本身并无对错好坏之分。本问卷实行匿名制，不 收集个人隐私数据, 所有数据将仅用于学术研究, 请放心填写。

注释： 1=非常不赞同； 2 =不赞同； 3 =不确定； $=$ =赞同； $5=$ =非常赞同

1. 我知道学好 ESP 对我来说会有用。[ ]

2. 我有学习 ESP 的意愿。 [ ]

3. 我不觉得学习 ESP 是在浪费时间。[ ]

4. 我觉得只有学好 ESP 才能在跨国企业中找到好工作。 [ ]

5. 如果能使用 ESP 进行国际商务活动, 将会让我获得更高收入。 [ ]

6. 我觉得学好 ESP 能让我在全球化背景下的国际市场中获得更广的人脉。 [ ]

7. 我学 ESP 的直接目的是为了在今后求职中 (无论是本土还是跨国企业) 能有更多的专业语言优势。[ ]

8. 我觉得如果无法熟练使用 ESP 与商业伙伴交流，会让我感到丢脸。［］

9. 我觉得在全球化背景下, 有必要学好 ESP, 这样才能真正融入到国际商业社会中。 [ ]

10. 我觉得有必要学好 ESP, 不然会被急速全球化的社会淘汰。[ ]

11. 我想成为掌握至少一门 ESP 的人。 [ ]

12. 我觉得学好 ESP 对我个人的职场发展有好处。 [ ]

13. 我觉得掌握 ESP 是一个人教育程度和身份修养的象征。[ ] 
14. 我觉得学习 ESP 是为了更好地从国际上获取所学专业的最新知识。 [ ]

15. 我觉得学习 ESP 是为了能更好地了解国际市场及其商业文化。 [ ]

16. 我觉得学好 ESP 能让我有种获取新知识、新技能带来的满足感。 [ ]

17. 我觉得如果能说好 ESP 会让我有种满足感。 [ ]

18. 我觉得学好 ESP 会让我有种超越自我的愉悦感。 [ ]

19. 我觉得学好 ESP 能让我更好地帮助中国与世界进行交流。 [ ]

20. 我觉得能说好 ESP 是一种时尚的事情。[ ]

21. 我觉得学好 ESP 能增强我的自信心。[ ]

22. 我觉得学好 ESP 能让我产生一种优越感。[ ]

23. 我觉得如果能用 ESP 与国际商业伙伴进行无障碍、高效交流, 会让我感到舒服。 [ ]

24. 如果您有其他看法, 请在以下方框内输入相关文字:

\section{Appendix B}

\section{A Questionnaire about the Learning Motivations of English for Specific Purposes}

\section{Dear students,}

We are an academic research team from Guangdong University of Foreign Studies. We are currently conducting a research on the learning motivations of non-English major learners in China when they learn English for Specific Purposes (hereinafter as ESP). We ask you to spend several minutes to finish this simple questionnaire.

Please select one score (from 1 to $5,5=$ totally agree, $4=$ agree, $3=$ not sure, $2=$ disagree, $1=$ totally disagree) for every statement according to your own thoughts. This survey does not intend to collect personal information, all data collected would be kept confidential and for academic research only.

Thank you!

1. I know learning ESP well would be useful for myself. [ ]

2. I have the willingness to learn ESP. [ ]

3. I don't think ESP learning is a waste of my time. [ ]

4. Only by learning ESP well could help me find a good job in a multinational corporation. [ ]

5. I would have a higher income if I could use ESP in international business activities. [ ]

6. Learning ESP well would enlarge my connection with professionals in the international marketplace. [ ]

7. I learn ESP in order to gain more advantage in terms of professional language when I apply for jobs in either domestic or multinational corporations.

8. I would feel ashamed if I could not use ESP skillfully to communicate with business partners. [ ]

9. I think it is necessary to learn ESP well under the circumstance of globalization, so as to integrate into the international business society. [ ]

10. It is necessary to learn ESP, otherwise I would be lagged behind in a society which is being rapidly globalized. [ ]

11. I want to be a person who masters more than one ESP. [ ] ]

12. I think it is good for my future career development if I could learn ESP well. [ ]

13. I think the mastery of ESP is a symbol of one's educational level and social status. [ ]

14. I intend to learn more about the latest development of my major study from the outside world. [ ]

15. I think leaning ESP is a way to better understand the global market and its business culture. [ ]

16. I think learning ESP well could bring me a sense of satisfaction by way of acquiring new knowledge and skill. [ ]

17. I think I would feel satisfied if I could speak ESP well. [ ] 
18. I think I could feel the pleasure of surpassing myself if I could learn ESP well. [ ]

19. I could help China communicate with the rest of the world better if I could learn ESP well. [ ]

20. I think it is fashionable to speak ESP well. [ ]

21. I think learning ESP well could boost my self-confidence. [ ]

22. I think learning ESP well could bring me a sense of superiority. [

23. I would feel comfortable if I could use ESP to communicate effectively with international business partners. [ ]

24. Please input your opinions other than the abovementioned ones in the following section:

\section{Copyrights}

Copyright for this article is retained by the author(s), with first publication rights granted to the journal.

This is an open-access article distributed under the terms and conditions of the Creative Commons Attribution license (http://creativecommons.org/licenses/by/3.0/). 